\title{
Erratum to: Complete nucleotide sequences of seven soybean mosaic viruses (SMV), isolated from wild soybeans (Glycine soja) in China
}

\author{
Yun-Xia Chen ${ }^{1} \cdot$ Mian Wu ${ }^{1} \cdot$ Fang-Fang Ma ${ }^{1} \cdot$ Jian-Qun Chen $^{1} \cdot$ Bin Wang $^{1}$
}

Published online: 23 January 2017

(C) Springer-Verlag Wien 2017

\section{Erratum to: Arch Virol}

DOI 10.1007/s00705-016-3163-6

In the original publication, accession numbers "KP834319KP834325" in section "Sequence properties" was incorrectly published. The correct accession number is "KX834319-KX834325".

The online version of the original article can be found under doi:10.1007/s00705-016-3163-6.

$\triangle$ Jian-Qun Chen

chenjq@nju.edu.cn

$凶$ Bin Wang

binwang@nju.edu.cn

1 Laboratory of Plant Genetics and Molecular Evolution, School of Life Sciences, Nanjing University, 163 XianLin Avenue, Nanjing 210023, China 